\title{
Is the Agricultural Work a Risk Factor for Koreans Elderly Spinal Sagittal Imbalance?
}

\author{
Jong-Hwan Hong, Moon-Soo Han, Seul-Kee Lee, Jung-Kil Lee, Bong Ju Moon \\ Department of Neurosurgery, Chonnam National University Medical School \& Research Institute of Medical Sciences, Gwangju, Korea
}

Objective : A primary degenerative sagittal imbalance has been considered because of unique lifestyles such as the prolonged crouched posture during agricultural work and performing activities of daily living on the floor. Previous papers have reported that sagittal imbalance disease is often seen distinctly in the farming districts of "oriental" countries such as Korea and Japan. However, this finding was only evaluated with the use of X-ray, and other factors such as magnetic resonance imaging (MRI), muscle volume, compression fracture, and laboratory results were not considered. Thus, using these, we evaluate the agricultural work-associated factors for Korean elderly spinal sagittal imbalance.

Methods : We recruited 103 Korean participants who had a sagittal vertical axis (SVA) of $>5 \mathrm{~cm}$ in this Korean Elderly Sagittal Imbalance Cohort Study. The following were evaluated : radiological parameters, MRI, compression fracture, vitamin D, parathyroid hormone, C-terminal telopeptide, osteocalcin, bone mineral density and muscle fatty change, muscle volume, and health-related quality of life from patients' survey. Moreover, in this survey, the farmers' annual working hours were investigated. Subsequently, we analyzed the associated factors for spinal sagittal imbalance depending on occupation.

Results : A total of 46 participants were farmers, and the others were housewives, sellers, and office workers. The farmer group had more SVA (141 vs. $99 \mathrm{~mm}, p=0.001)$ and pelvic tilt $\left(31^{\circ}\right.$ vs. $\left.24^{\circ}, p=0.004\right)$ and lesser lumbar lordosis $\left(20^{\circ}\right.$ vs. $\left.30^{\circ}, p=0.009\right)$ and thoracic kyphosis $\left(24^{\circ}\right.$ vs. $\left.33^{\circ}, p=0.03\right)$ than non-farmer group. A significantly positive correlation was noted between the working hour and SVA in the farmer group $(p=0.014)$. The visual analogue scale score for back pain $(8.26 \mathrm{vs.} 6.96, p=0.008)$ and Oswestry Disability Index ( 23.5 vs. 19.1, $p=0.003$ ) in the farmer group were higher than that in the non-farmer group, but the Short Form-36 score was not significantly different between the two groups. The Mini-Mental State Exam score was significantly lower in the farmer group than in the non-farmer group ( 24.85 vs. $26.98, p=0.002)$.

Conclusion : The farmer group had more sagittal imbalance and back pain in proportion to the working hours even though the muscle and bone factors and general laboratory condition were not significantly different between the two groups. These results supported that the long hours spent in the crouched posture while performing agricultural work were a risk factor for severe sagittal imbalance.

Key Words : Sagittal · Imbalance · Kyphosis · Quality of life · Agriculture.

- Received : March 27, $2020 \cdot$ Revised : April 28, $2020 \bullet$ Accepted : May 14, 2020

- Address for reprints : Bong Ju Moon

Department of Neurosurgery, Chonnam National University Hospital, 42 Jebong-ro, Dong-gu, Gwangju 61469, Korea

Tel : +82-62-220-6602, Fax : +82-62-224-9865, E-mail : bongjumoon@gmail.com, ORCID : https://orcid.org/0000-0003-1681-9734

This is an Open Access article distributed under the terms of the Creative Commons Attribution Non-Commercial License (http://creativecommons.org/licenses/by-nc/4.0) which permits unrestricted non-commercial use, distribution, and reproduction in any medium, provided the original work is properly cited. 


\section{INTRODUCTION}

Primary degenerative sagittal imbalance (PDSI) is a branch of adult spinal deformity from the perspective of global sagittal alignment ${ }^{14)}$. It was first described in Japan, which was thought to be attributed to a sedentary lifestyle and long squatting activity engaged in agriculture, ${ }^{4,16,17}$. Previous papers reported that PDSI is common in Asian agricultural regions such as Korea and Japan, but there is no significant progress in understanding this condition ${ }^{16,17,23)}$. Sagittal imbalance is common in elderly, and its prevalence rate ranges from $20 \%$ to $40 \%$. Moreover, it was thought to be an aging process but gradually recognized as a disease to be treated ${ }^{10)}$. Three components of the spinal column are involved in the transformation into a marked spinal deformity ${ }^{22}$. Especially in terms of health-related quality of life (HRQOL), it is one of the most significant topics in spinal diseases $^{2,8,14,24)}$. From the data of the United States and South Korea, as the population ages rapidly, the burden of degenerative spinal diseases also increases quickly ${ }^{7,15}$. Sagittal imbalance is thought to be a cumulative result of degeneration, but the exact impact factors are not clearly defined ${ }^{11}$. Although some authors reported that squatting and sedentary lifestyles are common in rural populations, the quantitative analysis of occupational factors for Koreans has not yet been elucidated ${ }^{16,23)}$. In the present study, we performed an assessment of the degree of sagittal imbalance and HRQOL between the agricultural and nonagricultural populations.

\section{MATERIALS AND METHODS}

\section{Study design}

This study was approved by the Institutional Review Board of Chonnam National University Medical School Research Institute (approval number CNUH-2016-127). For the purpose of the study, not the treatment, we recruited 103 Korean participants over 60 years old who had a sagittal vertical axis (SVA) of $>5 \mathrm{~cm}$ on whole-spine standing X-ray in this Korean Elderly Sagittal Imbalance Cohort Study. The exclusion criteria were as follows : 1) bed-ridden state; 2 ) impossible independent life; 3) previous history of spine or knee operation; 4) past history of Parkinson's disease or cerebrovascular disease; and 5) presence of severe infection and acute vertebral fracture and in quarantine. The participants were divided into two groups : farmer and non-farmer.

Face-to-face questionnaires were administered for HRQOL as follows : visual analogue scale (VAS) of the back and leg, Physical Component Summary (PCS)/Mental Component Summary (MCS) of Short Form-36 (SF-36), Oswestry Disability Index (ODI), and Mini-Mental State Exam (MMSE). In addition, telephone surveys were conducted on daily working hours and annual working periods. A working hour is defined as the product of daily working hours and annual working periods. The daily working time was defined as the time worked in a squatting position in a field during the day.

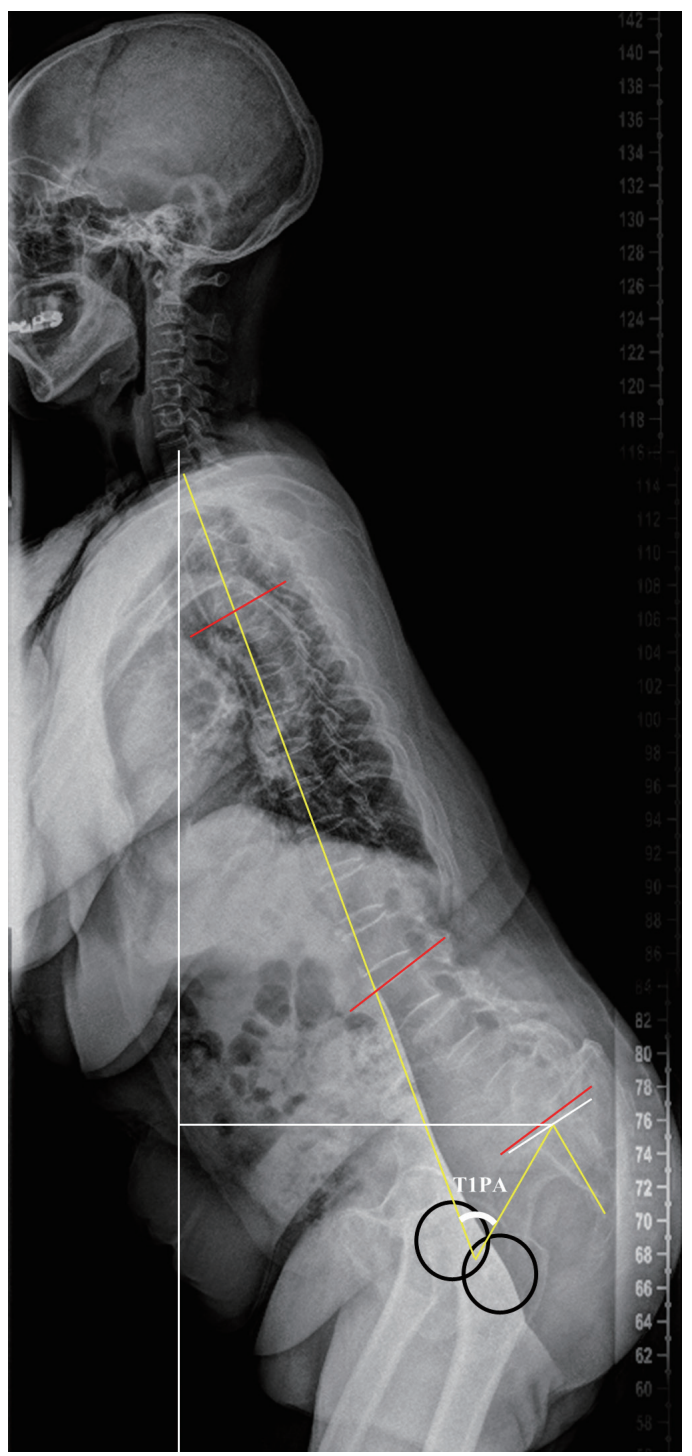

Fig. 1. Definitions of each radiologic parameter. The angle between the lines from the centroid of $\mathrm{T} 1$ to the femoral head axis and from the femoral axis to the middle of the S1 endplate. T1PA:T1 pelvic angle. 


\section{Data sources and variables}

Demographics such as age, sex, weight, height, and body mass index were examined in each group. Whole-spine X-ray, lumbar magnetic resonance imaging (MRI), bone mineral density (BMD), and plasma clinical chemistry were performed in each patient. The radiological parameters of sagittal imbalance were measured on whole-spine lateral X-ray based on the Scoliosis Research Society (SRS)-Schwab radiological classification, including SVA, thoracic kyphosis (TK), T1 pelvic angle (T1PA), lumbar lordosis (LL), pelvic incidence (PI), pelvic tilt (PT), sacral slope (SS), and compression fracture (Fig. 1).

The back and lumbar muscle volumes were measured by the total cross-sectional area (TCSA) of the psoas muscle (PS), lumbar multifidus muscle (MF), and lumbar erector spinae muscle (ES) from the patients' MRI image using the region of

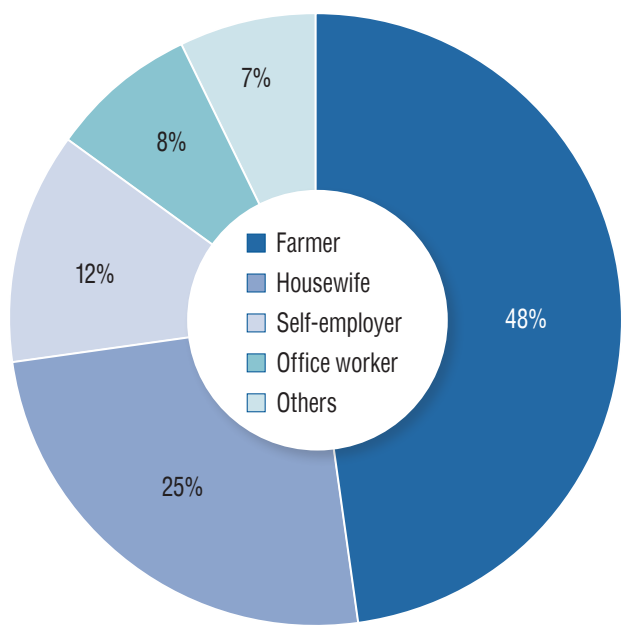

Fig. 2. Occupation of participants. There were 46 farmers and 50 nonfarmers. Non-agricultural occupations consisted of 24 housewives, 11 self-employed, 8 office workers, and 7 others. interest measurement tool of the picture archiving and communication system (M-view; INFINITT Healthcare, Seoul, Korea). In addition, fatty streaks of the lumbar muscle were measured from MRI according to the grading system by Battaglia et al. ${ }^{3)}$ and Goutallier et al. ${ }^{9}$.

Laboratory tests were performed on peripheral venous blood samples. Hemoglobin Alc (HbAlc), vitamin D, calcium ion, parathyroid hormone (PTH), C-terminal telopeptide (CTX), osteocalcin, rheumatoid factor, total cholesterol, triglyceride, high-density lipoprotein (HDL) cholesterol were measured.

\section{Statistics}

All data were analyzed using SPSS ver. 18.0 (SPSS Inc., Chicago, IL, USA). Demographics, radiological parameters, questionnaires, and laboratory values associated with spinal sagittal imbalance were evaluated between the two groups using t-test, chi-square test, and regression analysis. Pearson's correlation coefficient test was performed to analyze correlations between parameters. In the farmer group, a regression analysis was conducted to assure a correlation between the working hours and radiologic indicators. A $p$-value of $<0.05$ was considered significant. Described data are presented as mean \pm standard deviation.

\section{RESULTS}

\section{Demographics}

Seven participants were excluded from the study because they refused lumbar MRI scan. Consequently, there were 46

Table 1. Demographics of the farmer and non-farmer groups

\begin{tabular}{|c|c|c|c|}
\hline & Farmer $(n=46)$ & Non-farmer $(n=50)$ & $p$-value \\
\hline Age (years) & $72.85 \pm 4.23$ & $70.10 \pm 4.13$ & 0.001 \\
\hline Female (\%) & 76.0 & 86.0 & 0.214 \\
\hline Height (cm) & $154.04 \pm 7.55$ & $156.42 \pm 7.28$ & 0.120 \\
\hline Weight (kg) & $56.74 \pm 10.51$ & $59.84 \pm 8.86$ & 0.121 \\
\hline $\mathrm{BMI}\left(\mathrm{kg} / \mathrm{m}^{2}\right)$ & $23.82 \pm 3.96$ & $24.42 \pm 2.98$ & 0.204 \\
\hline Lumbar BMD & $-1.74 \pm 0.90$ & $-1.64 \pm 0.86$ & 0.607 \\
\hline Compression fracture & $15(32.6)$ & $13(26.0)$ & 0.508 \\
\hline Working hour* (hour-years) & $270 \pm 139$ & 0 & \\
\hline
\end{tabular}

Values are presented as mean \pm standard deviation or number (\%). *Working hour, flexed position on the ground, and 35 participants surveyed. BMI : body mass index, BMD : bone mineral density 
farmers and 50 non-farmers. Non-agricultural occupations consisted of housewives (25\%), self-employed (12\%), office workers (8\%), and others (7\%) (Fig. 2). The analyzed baseline statistics for each group are shown in Table 1.

The mean ages of the farmer and non-farmer groups were 72.85 and 70.1 years, respectively. The proportion of women in the farmer group was $76 \%$, and that of the other was $86 \%$. The farmer group showed lower height and weight than the non-farmer group. The BMD values at the lumbar spine and femur were relatively lower in the non-farmer group. However, no significant difference was found in the aforementioned values between the two groups. The average working hour in the farmer group was 270 hour-years (Table 1). The average working hour in the non-farmer group was 0 hour-years.

\section{Radiological findings}

The mean SVA values in the farmer and non-farmer groups were $14.16 \pm 6.13$ and $9.96 \pm 5.42 \mathrm{~cm}$, respectively $(p=0.001)$. The farmer group demonstrated significantly decreased LL $\left(20.05^{\circ}\right.$ vs. $\left.30.71^{\circ}, p=0.009\right)$ and TK $\left(24.16^{\circ}\right.$ vs. $\left.33.27^{\circ}, p=0.03\right)$ than the non-farmer group. Significant increases in PI-LL $\left(38.06^{\circ}\right.$ vs. $\left.24.29^{\circ}, p=0.003\right)$, PT (31.65 vs. $\left.24.82^{\circ}, p=0.004\right)$ and T1PA $\left(37.84^{\circ}\right.$ vs. $\left.28.29^{\circ}, p=0.004\right)$ were noted in the farmer group, which resulted from subsequent pelvic compensation. As the imbalance was more remarkable in the farmer group, the two groups showed significantly different amounts of pelvic compensation. The muscle volume and fatty change calculated as TCSA and Goutallier's grade of MF, ES, and PS were not significantly different between the two groups (Table 2). When the farmer group was analyzed separately, correlation analysis between SVA and other indicators was conducted in the agricul-

Table 3. Multivariate regression analysis between the working hours and radiological parameters on sagittal alignment of the farmer group

\begin{tabular}{lcc}
\hline & \multicolumn{2}{c}{ Farmer $(\mathbf{n = 3 5})$} \\
\cline { 2 - 3 } & $\boldsymbol{\beta} \pm \mathrm{SE}$ & $\boldsymbol{p}$-value \\
\hline SVA & $0.019 \pm 0.007$ & $0.014^{*}$ \\
TK & $0.008 \pm 0.023$ & 0.725 \\
T1PA $^{\dagger}$ & $0.024 \pm 0.019$ & 0.219 \\
LL & $-0.04 \pm 0.023$ & 0.096 \\
PI & $-0.016 \pm 0.015$ & 0.309 \\
PT & $-0.014 \pm 0.013$ & 0.313 \\
SS & $-0.001 \pm 0.018$ & 0.958 \\
PI-LL & $0.024 \pm 0.028$ & 0.390 \\
\hline
\end{tabular}

${ }^{*} p<0.05 .{ }^{\dagger}$ Invalid data excluded, 28 farmers and 41 non-farmers. SE : standard error, SVA : sagittal vertical axis, TK : thoracic kyphosis, T1PA : T1 pelvic angle, LL : lumbar lordosis, PI : pelvic incidence, PT : pelvic tilt, SS : sacral slope

Table 2. Comparison of radiological parameters on sagittal alignment between the farmer and non-farmer groups

\begin{tabular}{|c|c|c|c|}
\hline & Farmer $(n=46)$ & Non-farmer $(n=50)$ & $p$-value \\
\hline SVA (cm) & $14.16 \pm 6.13$ & $9.96 \pm 5.42$ & $0.001^{*}$ \\
\hline TK $\left({ }^{\circ}\right)$ & $24.16 \pm 16.85$ & $33.27 \pm 24.22$ & $0.034^{\dagger}$ \\
\hline $\operatorname{T1PA}^{\ddagger}\left({ }^{\circ}\right)$ & $37.84 \pm 13.37$ & $28.29 \pm 13.10$ & $0.004^{*}$ \\
\hline $\mathrm{LL}\left({ }^{\circ}\right)$ & $20.05 \pm 19.43$ & $30.71 \pm 19.92$ & $0.009^{*}$ \\
\hline $\mathrm{PI}\left({ }^{\circ}\right)$ & $58.11 \pm 11.74$ & $55.00 \pm 11.01$ & 0.184 \\
\hline $\mathrm{PT}\left({ }^{\circ}\right)$ & $31.65 \pm 11.00$ & $24.82 \pm 11.89$ & $0.004^{*}$ \\
\hline $\mathrm{SS}\left({ }^{\circ}\right)$ & $26.61 \pm 14.45$ & $30.12 \pm 9.35$ & 0.157 \\
\hline PI-LL (o) & $38.06 \pm 21.31$ & $24.29 \pm 22.53$ & $0.003^{*}$ \\
\hline TCSA MF & $704.84 \pm 193.60$ & $744.32 \pm 233.51$ & 0.375 \\
\hline TCSA ES & $1746.31 \pm 1317.09$ & $1559.48 \pm 340.83$ & 0.335 \\
\hline TCSA PS & $2328.51 \pm 505.96$ & $2384.20 \pm 417.71$ & 0.559 \\
\hline Goutallier MF & $2.18 \pm 0.83$ & $2.45 \pm 0.98$ & 0.154 \\
\hline Goutallier ES & $2.00 \pm 0.80$ & $2.12 \pm 0.98$ & 0.518 \\
\hline Goutallier PS & $2.04 \pm 0.74$ & $2.20 \pm 0.93$ & 0.371 \\
\hline
\end{tabular}

${ }^{*} p<0.01 .{ }^{\dagger} p<0.05$. ${ }^{\ddagger}$ Invalid data excluded, 28 farmers and 41 non-farmers. SVA : sagittal vertical axis, TK : thoracic kyphosis, T1PA : T1 pelvic angle, LL : lumbar lordosis, PI : pelvic incidence, PT : pelvic tilt, SS : sacral slope, TCSA : total cross-sectional area, MF : multifidus muscle, ES : erector spinae muscle, PS : psoas muscle 
tural group. There was no correlation with demographics, laboratory test or muscle quality other than working hour. In the multivariate regression analysis, between the working hours and radiological parameters, SVA had a significantly positive correlation $(p=0.014)$. Longer working hours was the only predicting factor for the higher SVA value. No other SVA-related values were identified, such as TK, T1PA, LL, PI, PT, SS, and PI-LL (Table 3).

\section{HRQOL}

Self-reported surveys including the back and leg VAS, SF-36 PCS and MCS, ODI, and MMSE were evaluated. The VAS scores for back pain were 8.26 for the participants in the farmer group and 6.96 for those in the non-farmer group. This difference was statistically significant $(p=0.008$ ). However, the VAS score for leg pain was not significantly different between the two groups. SF-36 PCS and MCS had lower scores in the farmer group than in the non-farmer group, but statistical significance was found only for PCS ( $p=0.027)$. The ODI showed significantly higher scores in the farmer group (23.5 vs. 19.12, $p=0.003$ ). Meanwhile, the results of the MMSE were significantly lower in the participants in the farmer group (24.85 vs. $26.98, p=0.002$; Table 4 ).

\section{Laboratory findings}

All laboratory tests including total cholesterol, HDL cholesterol, HbAlc, vitamin D, PTH, CTX, and osteocalcin had no difference between the two groups (Table 5).

Table 4. Comparison of HRQOL between the farmer and non-farmer groups

\begin{tabular}{lccc}
\hline & Farmer $(\mathbf{n}=\mathbf{4 6})$ & Non-farmer $(\mathbf{n}=\mathbf{5 0})$ & $\boldsymbol{p}$-value \\
\hline VAS back & $8.26 \pm 2.27$ & $6.96 \pm 2.44$ & $0.008^{*}$ \\
VAS leg & $7.15 \pm 2.69$ & $6.44 \pm 2.72$ & 0.201 \\
SF-36 PCS & $31.83 \pm 12.92$ & $38.06 \pm 14.24$ & 0.027 \\
SF-36 MCS & $45.09 \pm 14.48$ & $48.97 \pm 16.62$ & 0.227 \\
ODI & $23.50 \pm 7.73$ & $19.12 \pm 6.24$ & $0.003^{*}$ \\
MMSE & $24.85 \pm 3.77$ & $26.98 \pm 2.47$ & $0.002^{*}$ \\
\hline
\end{tabular}

${ }^{*} p<0.01$. HRQOL : health-related quality of life, VAS : visual analogue scale, SF-36 : Short Form-36, PCS : Physical Component Summary, MCS : Mental Component Summary, ODI : Oswestry Disability Index, MMSE : Mini-Mental State Exam

\section{DISCUSSION}

We are the first to describe that Korean elderly farmers were shown to have more severe sagittal imbalance. The average SVA of the farmer group was $14 \mathrm{~cm}$, which corresponds to the marked deformity of the SRS-Schwab classification ${ }^{25}$. T1PA was also higher in the farmer group, which is a sagittal alignment marker that compensates for the drawback that SVA is variable according to the measurer ${ }^{19)}$. The decrease in LL was even worse at $20^{\circ}$ in the farmer group. Compensatory sagittal balance changes resulted in more severe TK reductions in the farmer group. LL has evolved to adapt to promote upright posture in the human spine. Normal sagittal spine balance allows humanity to walk upright with minimal force ${ }^{20)}$. The LL loss causes more energy to maintain an upright posture, which worsens pain exacerbations and LL loss itself ${ }^{1,21}$. Eventually, severe sagittal imbalance results in more severe back pain and lower quality of life. Several studies have shown that sagittal imbalance is closely associated with poor HRQOL ${ }^{8)}$. In this study, back pain was more severe (VAS score for back pain, 8.26 vs. $6.96, p=0.008$ ), and life discomfort was more common in the farmer group as the result of SF-36 PCS and ODI score (23.5 vs. 19.12, $p=0.003$ ) showed.

Korean elderly farmers suffered from more severe sagittal imbalance, complained of more pain, and had lower quality of life. In Korea, work in the rural areas is frequently performed while sitting on the floor or squatting, often accompanied by a load of heavy lifting by bending at the waist (Fig. 3$)^{14)}$. In ad-

Table 5. Comparison of laboratory tests between the farmer and nonfarmer groups

\begin{tabular}{lccc}
\hline & Farmer $(\mathbf{n}=\mathbf{4 6})$ & Non-farmer $(\mathbf{n}=\mathbf{5 0})$ & $\boldsymbol{p}$-value \\
\hline Total cholesterol & $199.61 \pm 42.56$ & $198.26 \pm 48.67$ & 0.886 \\
TG & $133.25 \pm 95.17$ & $136.34 \pm 108.83$ & 0.883 \\
HDL & $56.13 \pm 14.32$ & $57.78 \pm 12.94$ & 0.555 \\
HbA1c & $5.74 \pm 0.56$ & $5.92 \pm 1.24$ & 0.367 \\
RF & $4.40 \pm 4.86$ & $7.43 \pm 13.36$ & 0.140 \\
Vitamin D & $23.80 \pm 8.02$ & $21.23 \pm 8.43$ & 0.131 \\
PTH & $46.56 \pm 19.19$ & $40.38 \pm 20.27$ & 0.132 \\
CTX & $0.42 \pm 0.20$ & $0.42 \pm 0.26$ & 0.971 \\
Osteocalcin & $21.04 \pm 8.17$ & $20.45 \pm 7.87$ & 0.723 \\
\hline
\end{tabular}

TG : triglyceride, HDL : high-density lipoprotein, $\mathrm{HbA1c}$ : hemoglobin A1c, RF : rheumatoid factor, PTH : parathyroid hormone, CTX : C-terminal telopeptide 


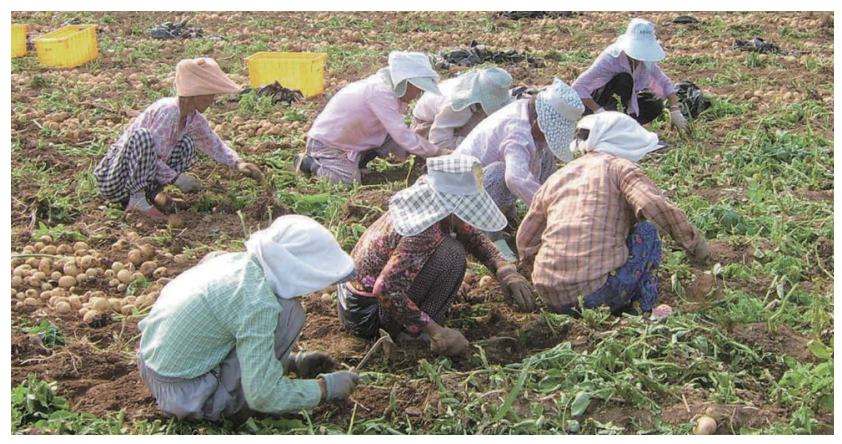

Fig. 3. A photograph showing female farmers working in a crouched posture on the ground in a farm in Korea. This photograph is courtesy of Korea Agency of Education, Promotion and Information Service in Food, Agriculture, Forestry and Fisheries.

dition, these areas are less modernized than cities, and several elderly people still live on the floor. Asian lifestyle, such as squatting and sitting on the floor without back support, is a common practice in East Asia, which causes back pain and poor quality of life. In the middle-aged Korean population, long hours of sedentary lifestyles have been reported to be associated with lower back pain ${ }^{12}$. Some reports have described that sitting or deep squatting without back support aggravates low back pain in the Korean rural population and middleaged women in China ${ }^{5,26)}$. In a Western study group, although the lumbar intervertebral disc pressure when sitting on a chair is higher than standing ${ }^{6}$, such pressure is increased in the squatting position, and stress on the lumbar spine is greater. Further study of spine kinetics in this regard may evolve the understanding of sagittal imbalance. The intramuscular pressure of the erectors spinae is higher in the squatting position than in the upright posture, which leads to the viscoelastic deformation of tissue structure, resulting in changes in tissue composition as well as muscle fatigue or soreness ${ }^{18}$. In regard to lower lumbar spinal muscle volume and more fatty degeneration in severe sagittal imbalance ${ }^{22}$, sedentary lifestyle in East Asia is also a factor associated with the muscle changes in such imbalance.

This study found a positive correlation between the agricultural working hour and SVA in the farmer group. To the best of our knowledge, this is the first report to show a statistically significant relationship between the working hour and SVA. In the correlation analysis of SVA on the farmer group, there was no correlation with demographics, laboratory test or muscle quality other than working hour. Radiological parameters or pain indicators have direct confounder effect with

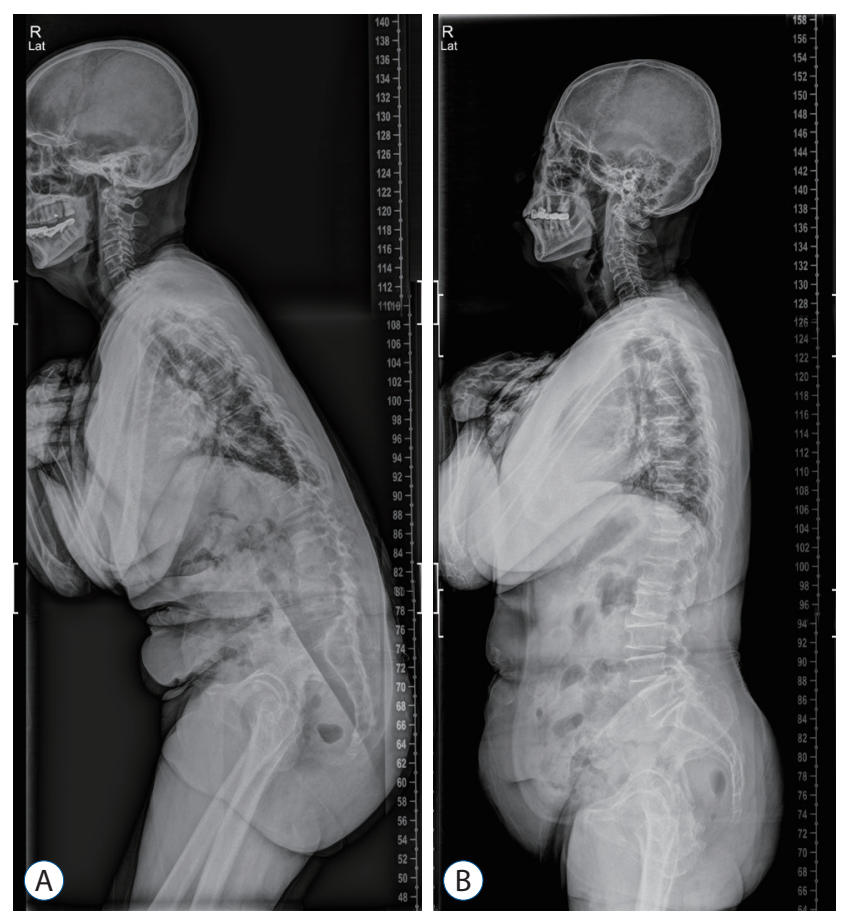

Fig. 4. The whole-body X-rays of two participants with different working hours and degrees of sagittal imbalance. $A$ : Working hour, 450 houryears; SVA, $18.7 \mathrm{~cm}$. B : Working hour, 250 hour-years; SVA, $5.2 \mathrm{~cm}$. SVA : sagittal vertical axis.

SVA, respectively, and when analyzing with working hours, the effect of working hours is underestimated. Although there was no significance in each individual parameter, it is notable that there is a correlation between the working hour and SVA. The SVA value is the most significant indicator for assessing the sagittal balance as an integrated value of the spinopelvic parameters. The participants in the farmer group who may be considered to have the heavy-duty floor life for a long time had, more severe sagittal imbalance compared with the nonfarmers (Fig. 4). From these results, to reduce PDSI, it should be suggested that farmers reduce their working hours in a sitting or squatting position and change to a standing lifestyle.

The MMSE score was also lower in the farmer group than in the non-farmer group. Failure to balance can result in not only pain, but also a decrease in forward-looking ability, which lead to social interaction ${ }^{13)}$. It is notable that the treatment of sagittal imbalance in the farmer group should be considered to not only pain, but also disability or function.

\section{Limitation}

This study has some limitations. Due to the characteristics 
of the cross-sectional and observational study, we could not clarify the causal relationship between measured indicators and agriculture. Although indicators were found to differ between the two groups, further follow-up studies are necessary to ascertain the causal relationship of whether the farmer group is the only factor affecting each indicator difference.

The method of checking annual working hours through telephone surveys can be biased in some ways. Memory-dependent assessments of elderly may not be accurately investigated, and it is difficult to reflect consistency or continuity of working hours. If the squatting posture during the day except for working hours was analyzed in the two groups, the confounder of the daily life pattern might be excluded, but there may be bias due to insufficient investigation of these parts. Nevertheless, the daily sedentary life pattern is generally not considered to be different between participants, so this study focusing on working hours in a deep squatting posture is pertinent.

There is no model or findings that could fully demonstrate the understanding of how the squatting posture advances sagittal imbalance. Further biomechanical research would be necessary, such as disc degeneration and difference of axial loading point during squatting position to determine the effect of SVA and loss of lordosis.

\section{CONCLUSION}

Sagittal imbalance and back pain were worse in the Korean elderly farmers compared with those in non-famers. Longer working hours of agricultural workers resulted in higher SVA. These findings showed the long hours spent in the crouched posture while performing agricultural work was a risk factor for severe sagittal imbalance. To reduce PDSI, it should be suggested that farmers reduce their working hours in a sitting or squatting position and change to a standing lifestyle.

\section{CONFLICTS OF INTEREST}

No potential conflict of interest relevant to this article was reported.

\section{INFORMED CONSENT}

Informed consent was obtained from all individual participants included in this study.

\section{AUTHOR CONTRIBUTIONS}

\author{
Conceptualization : BJM, JKL \\ Data curation : JHH \\ Formal analysis : BJM \\ Funding acquisition : JKL \\ Methodology : BJM \\ Project administration : BJM \\ Visualization : SKL \\ Writing - original draft : JHH, BJM \\ Writing - review \& editing : MSH, JHH
}

\section{ORCID}

Jong-Hwan Hong https://orcid.org/0000-0002-7864-1145

Moon-Soo Han https://orcid.org/0000-0001-9594-1193

Seul-Kee Lee https://orcid.org/0000-0002-4297-6234

Jung-Kil Lee https://orcid.org/0000-0002-9143-4917

Bong Ju Moon https://orcid.org/0000-0003-1681-9734

\section{References}

1. Ailon $T$, Smith JS, Shaffrey $C l$, Lenke LG, Brodke $D$, Harrop JS, et al. : Degenerative spinal deformity. Neurosurgery 77 Suppl 4 : S75-S91, 2015

2. Ames CP, Scheer JK, Lafage V, Smith JS, Bess S, Berven SH, et al. : Adult spinal deformity: epidemiology, health impact, evaluation, and management. Spine Deform 4 : 310-322, 2016

3. Battaglia PJ, Maeda Y, Welk A, Hough B, Kettner N : Reliability of the Goutallier classification in quantifying muscle fatty degeneration in the lumbar multifidus using magnetic resonance imaging. J Manipulative Physiol Ther 37 : 190-197, 2014

4. Bess S, Line B, Fu KM, McCarthy I, Lafage V, Schwab F, et al. : The health impact of symptomatic adult spinal deformity: comparison of deformity types to United States population norms and chronic diseases. Spine (Phila Pa 1976) 41 : 224-233, 2016

5. Cho NH, Jung YO, Lim SH, Chung CK, Kim HA : The prevalence and risk factors of low back pain in rural community residents of Korea. Spine (Phila Pa 1976) 37 : 2001-2010, 2012 
6. Claus A, Hides J, Moseley GL, Hodges P : Sitting versus standing: does the intradiscal pressure cause disc degeneration or low back pain? J

Electromyogr Kinesiol 18 : 550-558, 2008

7. Department of Economic and Social Affairs United Nations : World population ageing, 1950-2050. New York: United Nations, 2002

8. Glassman SD, Berven S, Bridwell K, Horton W, Dimar JR : Correlation of radiographic parameters and clinical symptoms in adult scoliosis. Spine (Phila Pa 1976) 30 : 682-688, 2005

9. Goutallier D, Postel JM, Bernageau J, Lavau L, Voisin MC : Fatty muscle degeneration in cuff ruptures. Pre- and postoperative evaluation by CT scan. Clin Orthop Relat Res (304) : 78-83, 1994

10. Kado DM, Prenovost $K$, Crandall $C:$ Narrative review: hyperkyphosis in older persons. Ann Intern Med 147 : 330-338, 2007

11. Kim KT, Lee SH, Suk KS, Lee JH, Im YS, Seo EM : Loss of sagittal balance and clinical outcomes following corrective osteotomy for lumbar degenerative kyphosis. J Korean Orthop Assoc 44 : 83-92, 2009

12. Kim MJ, Ahn KY, Jeon YJ : Association of type of physical activity and sedentary time with lower back pain in Korean above 50 years : Korean National Health and Nutrition Examination Survey VI 2014. Korean Soc Sports Sci 25 : 1107-1120, 2016

13. Le Huec JC, Faundez A, Dominguez D, Hoffmeyer P, Aunoble S : Evidence showing the relationship between sagittal balance and clinical outcomes in surgical treatment of degenerative spinal diseases: a literature review. Int Orthop 39 : 87-95, 2015

14. Lee CH, Chung CK, Jang JS, Kim SM, Chin DK, Lee JK : 'Lumbar degenerative kyphosis' is not byword for degenerative sagittal imbalance: time to replace a misconception. J Korean Neurosurg Soc 60 : 125-129, 2017

15. Lee $\mathrm{CH}$, Chung $\mathrm{CK}$, Kim CH, Kwon JW : Health care burden of spinal diseases in the Republic of Korea: analysis of a nationwide database from 2012 through 2016. Neurospine 15 : 66-76, 2018

16. Lee CS, Kim YT, Kim E : Clinical study of lumbar degenerative kyphosis. J Korean Soc Spine Surg $4:$ 27-35, 1997

17. Lee SH, Kim KT, Suk KS, Lee JH, Seo EM, Huh DS : Sagittal decompensa- tion after corrective osteotomy for lumbar degenerative kyphosis: classification and risk factors. Spine (Phila Pa 1976) 36 : E538-E544, 2011

18. Mueller G, Morlock MM, Vollmer M, Honl M, Hille E, Schneider E : Intramuscular pressure in the erector spinae and intra-abdominal pressure related to posture and load. Spine (Phila Pa 1976) 23 : 2580-2590, 1998

19. Protopsaltis T, Schwab F, Bronsard N, Smith JS, Klineberg E, Mundis G, et al. : TheT1 pelvic angle, a novel radiographic measure of global sagittal deformity, accounts for both spinal inclination and pelvic tilt and correlates with health-related quality of life. J Bone Joint Surg Am 96 : 1631-1640, 2014

20. Roussouly P, Gollogly S, Berthonnaud E, Dimnet J : Classification of the normal variation in the sagittal alignment of the human lumbar spine and pelvis in the standing position. Spine (Phila Pa 1976) 30 : 346353, 2005

21. Roussouly P, Pinheiro-Franco $\mathrm{JL}$ : Biomechanical analysis of the spinopelvic organization and adaptation in pathology. Eur Spine J 20 Suppl 5(Suppl 5) : 609-618, 2011

22. Ryu DS, Shinn JK, Kim BW, Moon BJ, Ha Y, Lee JK, et al. : Prospective observational cohort study of health-related quality of life: marked adult sagittal deformity (ASD) in comparison with mild to moderate ASD. Spine (Phila Pa 1976) 44 : 1723-1730, 2019

23. Takemitsu Y, Harada Y, Iwahara T, Miyamoto M, Miyatake Y : Lumbar degenerative kyphosis. Clinical, radiological and epidemiological studies. Spine (Phila Pa 1976) 13 : 1317-1326, 1988

24. Taneichi $\mathrm{H}$ : Update on pathology and surgical treatment for adult spinal deformity. J Orthop Sci 21 : 116-123, 2016

25. Terran J, Schwab F, Shaffrey Cl, Smith JS, Devos P, Ames CP, et al. : The SRS-Schwab adult spinal deformity classification: assessment and clinical correlations based on a prospective operative and nonoperative cohort. Neurosurgery 73 : 559-568, 2013

26. Yip YB, Ho SC, Chan SG : Identifying risk factors for low back pain (LBP) in Chinese middle-aged women: a case-control study. Health Care Women Int 25 : 358-369, 2004 